\title{
Time for Two Annual Turing Awards
}

\section{It is the season when we recognize an extraordinary research contribution to computing with the ACM A.M. Turing Award. I propose a change.}

ACM should bestow two Turing Awards each year, starting immediately. I do not mean to two people; a number of Turing Awards have been shared. But rather, my position is that the ACM should award several Turing Awards every year. These awards could be staggered by six months, perhaps in spring and fall, to ensure each winner receives the focused attention of the computing community and the world they richly deserve. This attention properly focuses on their research accomplishments and impact on the world.

Why give two Turing Awards?

Since the Turing Award was first given in 1966, the scope and impact of computing has grown immeasurably. At that time, more than 50 years ago, there were dozens of computers sold each year, with a few hundred computers in the world. By 2000, as the Internet transformed the world, computer sales had increased 10 million-fold, with PCs exceeding 120 million per year, with half a billion computers in the world. With the advent of smartphones, annual sales have grown by another 10-fold, exceeding 1.5 billion each year, with over five million "apps." Perhaps invention has not grown linearly with the number of computers, but as scholars of innovation would expect at least $\mathrm{n}^{0.5}$ rates $\left(10,000\right.$-fold) or even at $\log _{2} \mathrm{n}$ rates (25fold). These represent phenomenal growth in innovation in computing.

But there are more measures of growth. The number of programmers worldwide (25 million software developers) and computer science researchers (over 24,000 published authors in the ACM Digital Library) are extraordinary, driving an incredible rate of invention and innovation. And in recent decades, the computing community has grown dramatically in China, India, and throughout Asia, South America, Arabia, and Africa. Among that dramatic breadth of activity, how can it be that only one is worthy of a Turing Award each year?

We know that it cannot be. It's the right thing for ACM to broaden its recognition by granting two Turing Awards each year. But not only is it the right thing to recognize extraordinary leaders, but it's good to promote the field of computing. A Turing Award is a recognition, empowering more

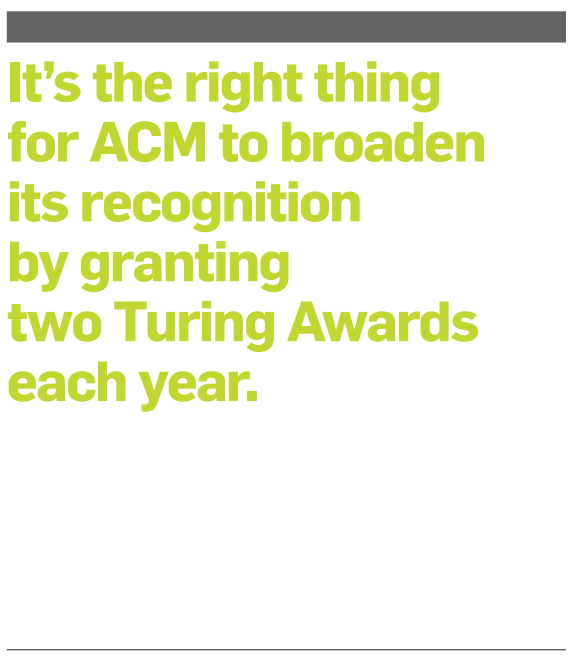

computing champions and leaders!

Why now? Well to speak frankly, it's already long overdue. We should have expanded to multiple Turing Awards in the 1980s when computers exploded into the lives of ordinary people with the spread of the $\mathrm{PC}$, and leading to an explosion of business, entertainment and personal applications. We should have expanded to multiple Turing Awards in the late 1990s when the explosive growth of the Internet transformed information access, music sharing, and connected the world at a speed and breadth unimaginable in human history. And yes, we should have expanded to multiple Turing Awards in the 2010s as smartphones transformed the personal and business lives of billions around the world.

Let's do it now! Starting now, the ACM must increase the recognition of extraordinary contributions to computing being made by leading researchers today by increasing the number of Turing Awards granted each year to two!

Please lend your voice by writing to me (eic@cacm.acm.org) or commenting on the Web.

Andrew A. Chien, EDITOR-IN-CHIEF

Andrew A. Chien is the William Eckhardt Distinguished Service Professor in the Department of Computer Science at the University of Chicago, Director of the CERES Center for Unstoppable Computing, and a Senior Scientist at Argonne National Laboratory.

Copyright held by author/owner. 